\title{
Noonan syndrome-like disorder with juvenile myelomonocytic leukemia
}

INSERM

\section{Source}

INSERM. (1999). Orphanet: an online rare disease and orphan drug data base. Noonan syndrome-like disorder with juvenile myelomonocytic leukemia. ORPHA:363972

Noonan syndrome-like disorder with juvenile myelomonocytic leukemia is a rare, genetic, polymalformative syndrome with increased risk of developing cancer characterized by a Noonan-like phenotype, including typical dysmorphic facial features (i.e. high forehead, hypertelorism, downslanting palpebral fissures, ptosis, low-set ears, prominent philtrum and short neck with or without pterygium colli), thoracic abnormalities, congenital heart defects and short stature, associated with a very frequent ocurrence of juvenile myelomonocytic leukemia. Developmental delay, ectodermal anomalies, joint laxity, and hypotonia may also be associated. 